\title{
Prospective Study on Clinical and Hematological Profile of Dengue Infection Cases in a Teaching Hospital in Bachupally Area, Hyderabad, Telangana
}

\author{
Nagendra Prasad ${ }^{1}$, M. Kanya Kumari ${ }^{2}$ \\ ${ }^{1}$ Assistant Professor, Department of General Medicine, Mamata Academy of Medical Sciences, Bachupally, Hyderabad, \\ Telangana, ${ }^{2}$ Professor, Department of Pathology, Mamata Academy of Medical Sciences, Bachupally, Hyderabad, Telangana, \\ India
}

Corresponding author: Dr. M. Kanya Kumari, Professor, Department of Pathology, Mamata Academy of Medical Sciences, Bachupally, Hyderabad, Telangana, India

DOI: http://dx.doi.org/10.21276/ijcmsr.2020.5.1.10

BY-NC-ND

How to cite this article: Nagendra Prasad, M. Kanya Kumari. Prospective study on clinical and hematological profile of dengue infection cases in a teaching hospital in Bachupally Area, Hyderabad, Telangana. International Journal of Contemporary Medicine Surgery and Radiology. 2020;5(1):A43-A46.

\section{A B S T R A C T}

Introduction: Dengue is a common and important viral disease in India. This disease is transmitted by the Aedes aegypti mosquitoes. It has varied clinical presentation from simple fever to dengue shock syndrome to death. In many cases the simple hematological parameters show variations and guide the patient management. The aim of the study was to determine the clinical and hematological profile in patients with Dengue infection.

Material and Methods: This was a prospective study done in the department of General Medicine at Mamata Academy of Medical Sciences, Hyderabad, Telangana, over a duration of one year. A total of 120 admitted dengue cases were studied for patient demographics, clinical presentation, hematological and serological profile, limited biochemical profile. Ultrasound abdomen was done wherever necessary.

Results: Maximum number of cases 74/120 (61.6\%) were seen in the 18-30 years age. The male to female ratio was 3.2:1. Fever was the most common presentation and was seen in all 120 cases (100\%) cases. Most of the cases were found in the monsoon and post monsoon period in August, September and October. Hemo concentration ( $>47 \%$ ) was noted in $50 / 120$ $(41.6 \%)$ of patients. Leucopenia was present in $80 / 120(66.6 \%)$ cases. Very severe thrombocytopenia was seen in $38.3 \%$ $(46 / 120)$ cases. Serum AST and ALT were mildly elevated in 78 (65\%) cases and were normal in 42 (35\%) cases.

Conclusion: The clinical presentation of Dengue fever is varied and most often presents with fever, myalgia and headache. It commonly affects young adult males. It often gives rise to an elevated hematocrit, low total leucocyte count and thrombocytopenia. Serological tests help to differentiate between a primary and secondary infection which is very important as the latter is associated with hemorrhagic and shock syndromes.

Keywords: Dengue Fever, Platelet Count, Leucopenia, NS1Ag, Severe Thrombocytopenia

\section{INTRODUCTION}

Dengue is an acute mostly self-limited systemic viral infection caused by the dengue virus belonging to the family flaviviridae. ${ }^{1}$ Incidence of dengue fever (DF) has been increasing from past few years and dengue has become a global problem in recent times. ${ }^{2}$ Dengue fever is an acute febrile disease characterized by sudden onset of fever of 3 to 5 days, intense headache, myalgia, retro-orbital pain, anorexia, gastrointestinal disturbances and rashes. ${ }^{3}$ The hematological effects observed are changes in blood counts, hemoconcentration due to plasma leakage, leucopenia because of decreased neutrophils near the end of the febrile phase, presence of atypical lymphocytes and relative lymphocytosis before shock, thrombocytopenia and changes in blood hemostasis with frequent presence of hemorrhagic manifestations. ${ }^{4}$
The etiologic agents include all four serotypes which belong to the genus flavivirus in the family flaviviridae. The principal vector is the mosquito, Aedes aegypti, which breeds largely indoors in artificial water containers, and feeds on humans in day time. ${ }^{5}$

The aim of the study was to determine the clinical and hematological profile in Dengue fever patients in Bachupally area, Hyderabad, Telangana.

\section{MATERIAL AND METHODS}

This was a prospective study done in the departments of general Medicine and Pathology at Mamata Academy of Medical Sciences, Bachupally, Hyderabad, Telangana state over a period of one year from June 2018 to August 2019.

A total of 120 cases of dengue fever admitted in the wards under dept of General medicine were studied. The patients were labeled as belonging to either of the following categories: 
Classical Dengue Fever (DF) or Dengue Haemorrhagic fever (DHF) or Dengue shock syndrome (DSS). Prior permission was taken from the Institutional Ethical committee.

\section{Inclusion criteria}

Patients willing to participate

Age group from 18 years to more than 70 years.

Patients with serologically confirmed IgM positive dengue fever admitted to General Medicine ward.

Both genders.

\section{Exclusion criteria}

Patients not willing to participate

Age below 18 years

Admitted patients with non-dengue medical conditions

Patients who were having both Dengue fever and Malaria

All the cases that were dengue seropositive were selected.

A thorough clinical history was taken. Local and systemic examination was done in all cases included in the study. All the routine investigations like complete blood count (Hematology autoanalyser Sysmax xs-800i), peripheral blood film for cell morphology, thick and thin blood smears for malaria parasite, specific malarial antigen card test, random blood sugar, complete urine analysis, Liver function tests (LFT) were done. Dengue IgM and IgG by ELISA was done in all the cases.

For routine investigations, $2 \mathrm{ml}$ venous blood sample was collected in EDTA tubes from the cubital vein from all the patients.

Hematological parameters such as Haemoglobin percentage, Haematocrit, Platelet count, Total leucocyte count, Differential leucocyte count was done in the autoanalyser.

Activated partial thromboplastin time and prothrombin time (APTT/PT) was done by collecting $2 \mathrm{ml}$ blood in sodium citrate anticoagulant containers. For serological investigations, $2 \mathrm{ml}$ patient blood was collected in red colored vacuatainer for $\operatorname{IgM}$ and $\operatorname{IgG}$ testing by Enzyme Linked Immunosorbent Assay (ELISA) method and for NS1-Ag (Nonstructural protein-1 antigen) test.

Dengue day1 test kit was used to detect NS1 antigen and $\operatorname{IgM}$ and $\operatorname{IgG}$ antibodies. The test results were expressed as positives/negatives for antigen and antibodies.

Ultrasound (USG) abdomen was done in those cases which also had ascites.

\section{RESULTS}

According to age distribution, maximum number of cases $74 / 120(61.6 \%)$ were in the 18 to 30 years group (table-1).

Gender distribution: Majority of the patients were males 92/120 (76.6\%) compared to females, 28/120 (23.3\%) and the male to female ratio was 3.2:1.

Only fever was the most common presentation and was seen in $96 / 120$ cases (75\%) cases (table-2).

Seasonal variation: Our study showed most of the cases in the monsoon and post-monsoon periods in the months of August, September and October which accounted for 80 (66.6\%) cases. The remaining $40(33.3 \%)$ cases were seen spread throughout the remaining months.

Hematological parameters: The hemoglobin, hematocrit,

\begin{tabular}{|l|c|c|}
\hline Age (in years) & No. of cases & Percent (\%) \\
\hline $18-30$ & 74 & $61.6 \%$ \\
\hline $31-40$ & 17 & $14.1 \%$ \\
\hline $41-50$ & 18 & $15 \%$ \\
\hline $51-60$ & 8 & $6.6 \%$ \\
\hline $61-70$ & 03 & $2.5 \%$ \\
\hline Total & 120 & $100 \%$ \\
\hline \multicolumn{2}{|c|}{ Table-1: Age distribution of the cases } \\
\hline
\end{tabular}

\begin{tabular}{|l|c|c|}
\hline Clinical features* & $\begin{array}{c}\text { No. of } \\
\text { cases }\end{array}$ & Percent (\%) \\
\hline Only Fever & 96 & $75 \%$ \\
\hline Fever with Myalgia & 46 & $38.3 \%$ \\
\hline Myalgia+Headache & 38 & $31.6 \%$ \\
\hline Fever+Headache & 11 & $9.1 \%$ \\
\hline Nausea and vomiting & 9 & $7.5 \%$ \\
\hline Skin rashes/petechiae & 16 & $13.3 \%$ \\
\hline Fever and mild pain in abdomen & 12 & $10 \%$ \\
\hline $\begin{array}{l}\text { *Symptoms were not mutually exclusive and many patients } \\
\text { had more than one symptom. }\end{array}$ \\
\hline \multicolumn{2}{|c|}{ Table-2: Distribution of Clinical features } \\
\hline
\end{tabular}

\begin{tabular}{|l|c|c|}
\hline Hb (gm/dl) & No. of cases & Percent (\%) \\
\hline $6-8.9$ & 10 & $8.3 \%$ \\
\hline $9-11.9$ & 20 & $16.6 \%$ \\
\hline $12-14.9$ & 40 & $33.3 \%$ \\
\hline $15-17.9$ & 50 & $41.6 \%$ \\
\hline Total & 120 & $100 \%$ \\
\hline Table-3: Distribution of study population based on hemoglobin \\
\hline
\end{tabular}

\begin{tabular}{|l|c|c|}
\hline Hct (\%) & No. of cases & $\%$ \\
\hline $20-26$ & - & - \\
\hline $27-36$ & 30 & $25 \%$ \\
\hline $37-46$ & 40 & $33.3 \%$ \\
\hline $47-56$ & 50 & $41.6 \%$ \\
\hline Total & 120 & $100 \%$ \\
\hline
\end{tabular}

Table-4: Distribution of study population based on hematocrit level

\begin{tabular}{|l|c|c|}
\hline TLC (cells/cumm) & No. of cases & $\%$ \\
\hline$<1500$ & - & - \\
\hline $1500-4,000$ & 80 & $66.6 \%$ \\
\hline $4000-11,000$ & 25 & $20.8 \%$ \\
\hline$>11,000$ & 15 & $12.5 \%$ \\
\hline Total & 120 & $100 \%$ \\
\hline \multicolumn{2}{|c|}{ Table-5: Distribution of cases according to total leukocyte } \\
count
\end{tabular}

\begin{tabular}{|l|c|c|}
\hline Platelets (cells/cumm) & No. of cases & Percent (\%) \\
\hline$<20,000$ & 46 & $38.3 \%$ \\
\hline $20,000-50,000$ & 28 & $23.3 \%$ \\
\hline $50,000-1$ lakh & 22 & $18.3 \%$ \\
\hline 1-1.4 lakh & 24 & $20 \%$ \\
\hline Total & 120 & $100 \%$ \\
\hline \multicolumn{2}{|c|}{ Table-6: Distribution of cases according to platelet count } \\
\hline
\end{tabular}




\begin{tabular}{|l|c|c|}
\hline USG & $\begin{array}{c}\text { No. of cases } \\
\text { (Dengue fever) } \\
\text { DF }\end{array}$ & $\begin{array}{c}\text { No. of cases } \\
\text { (Dengue hemor- } \\
\text { rhagic fever) DHF }\end{array}$ \\
\hline Pleural effusion & 10 & 50 \\
\hline Ascites & 05 & 30 \\
\hline Hepatomegaly & 20 & 40 \\
\hline Splenomegaly & 50 & 30 \\
\hline \multicolumn{2}{|c|}{ Table-7: Ultrasonographic findings } \\
\hline
\end{tabular}

total leucocyte count and platelet count were tabulated. Increased hemoglobin levels were observed in $41.6 \%$ cases (table-3).

Haemo concentration (>47\%) was noted in 50/120 (41.6\%) of patients (table-4).

Leucopenia with less than 4000 cells/cumm was present in 80/120 (66.6\%) cases (table-5).

In the present study out of 120 cases of dengue fever, $38.3 \%$ $(46 / 120)$ cases had very severe thrombocytopenia of less than $20,000 /$ cumm platelet count. The cases with platelets less than 20,000/cumm with bleeding manifestations received fresh SDP (single donor platelets) from our Institute Blood Bank by platelet apheresis technique and with platelet transfusion monitoring. Few cases were also transfused with fresh RDP and FFP (table-6).

Moderate thrombocytopenia was seen in $18.3 \%(22 / 120)$ cases. The cases with moderate thrombocytopenia with bleeding manifestations received SDP (single donor platelets).

Mild thrombocytopenia was observed in 20\% (24/120) cases. These cases were observed and monitored for platelets regularly and given symptomatic treatment without any platelet transfusions.

Distribution of patients according to activated partial thromboplastin time: This test showed normal values in 90 (75\%) cases and it was elevated in $30(25 \%)$ cases.

Elevated liver enzymes: Serum AST and ALT were mildly elevated in $78(65 \%)$ cases and were normal in $42(35 \%)$ cases.

Serology: All the cases were positive for NS1Ag test. Also based on serum IgM and IgG testing it was observed that $65 \%(78 / 120)$ cases were primary infections and 35\% $(42 / 120)$ were secondary infections.

Coagulation profile was deranged in 5 patients $(4.1 \%)$ with $\mathrm{DHF}$ and in none of the patients with only DF (table-7). Microscopic examination of urine sample showed evidence of hematuria in 10/120 (8.3\%) of the patients in the study.

\section{DISCUSSION}

Sample size: In the present study a total of 120 patients with dengue fever and DHF were included. Meena KC et $\mathrm{al}^{6}$ studied a sample size of total 100 patients, Tewari et $\mathrm{al}^{7}$ studied 443 adult patients, Deshwal et a ${ }^{8}$ studied a total of 515 patients and Khatroth $\mathrm{S}^{9}$ studied 60 patients for dengue fever. There are many studies on dengue fever from India as it has become an endemic disease here with spikes occurring during mosquito breeding seasons.

Age distribution: In our study maximum number of cases
$74 / 120(61.6 \%)$ were observed in the 18 to 30 years age group. In a study by Bhurke et $\mathrm{al}^{10}$ highest number of cases were from 12-20 years (33\%) age group. Meena $\mathrm{KC}$ et al ${ }^{6}$ observed maximum cases (29\%) in 21-30 years and Khatroth $\mathrm{S}^{9}$ observed most of their cases (50\%) in the 20-30 year age group. Deshwal et a ${ }^{8}$ also reported maximum patients in 21 40 year age group (62.91\%). Our findings compare well with the above authors.

Gender distribution: In the present study, majority of the patients were males 92/120 (76.6\%) compared to females 28/120 (23.3\%) and the male to female ratio was 3.2:1. This was correlating with other studies such as Meena $\mathrm{KC}$ et a ${ }^{6}$ who too reported a male preponderance with $63 \%$ males and $37 \%$ females. Tewari et $\mathrm{al}^{7}$ reported an almost equal incidence in males and males ( $\mathrm{n}=443$ adult patients, 223 were males and 220 were females). Other authors have also reported a definite male predominance with $72.81 \%$ in the study by Deshwal et al ${ }^{8}$ and and $66.6 \%$ by Khatroth S. ${ }^{9}$ Nair et $\mathrm{al}^{11}$ have reported a slight female preponderance with $53 \%$ females and $47 \%$ males.

Clinical symptoms: In the present study, fever was the most common presentation and was seen in all 120 (100\%) cases. Other studies ${ }^{7,8,9,10,11}$ have also observed fever as the most common clinical presentation of dengue fever followed by headache. The more severe forms of dengue infection like the dengue hemorrhagic fever (DHF) and dengue shock syndrome (DSS) are mainly seen in cases of secondary dengue infection. ${ }^{12}$

Seasonal variation: Our study showed most of the cases in the monsoon and post-monsoon periods in the months of August, September and October which accounted for 80 (66.6\%) cases. The remaining $40(33.3 \%)$ cases were seen spread throughout the remaining months. Khatroth $\mathrm{S}^{9}$ also observed most of their cases $25(41.6 \%)$ and $17(28.3 \%)$ in the post monsoon period in September and October months respectively.

Deshwal et $\mathrm{al}^{8}$ also observed majority of their cases occurring in the rainy season coinciding with the breeding of mosquitoes during this period.

Hematological findings: In the present study, hemoconcentration $(>47 \%)$ was noted in 50/120 (41.6\%\%) of patients with DHF. Khatroth $\mathrm{S}$ et $\mathrm{al}^{9}$ observed raised hematocrit $(>47 \%)$ in $10(16.6 \%)$ of patients at presentation. Deshwal et $\mathrm{al}^{8}$ also observed elevated hematocrit $(>45 \%)$ in $20.77 \%$ of patients at presentation. Dengue fever and DHF are associated with the capillary leak syndrome that results in hemoconcentration.

In the present study it was observed that leucopenia was present in a significant number of patients with DF and DHF. Leucopenia with less than 4000 cells/cumm was present in 80/120 (66.6\%) cases. Meena KC et al ${ }^{6}$ also observed leucopenia of less than 4,000 cells/cumm in 51 (51\%) of their patients.

In the present study out of 120 cases of dengue fever, $38.3 \%$ $(46 / 120)$ cases had very severe thrombocytopenia. Meena $\mathrm{KC}$ et $\mathrm{al}^{6}$ noted severe thrombocytopenia with bleeding in $14 \%$ cases. Petechial manifestation was the most common 
manifestation. Deshwal et $\mathrm{al}^{8}$ reported low platelet counts of less than 50,000/cumm in around $69.51 \%$ of their cases.

In our study out of 120 patients, 74 (61.6\%) patients were diagnosed to have DF, 46 (38.3\%) patients were diagnosed to have DHF. In Meena KC et $\mathrm{al}^{6}$ study, out of 100 patients, 84 (84\%) patients were diagnosed to have DF,14 (14\%) patients were diagnosed to have DHF and $2(2 \%)$ patients were diagnosed to have the more severe dengue shock syndrome (DSS) based on WHO criteria. Bhurke et al ${ }^{10}$ observed that majority of their cases (81\%) had DF, $19 \%$ had DHF, while none had DSS.

In the present study serum AST and ALT were mildly elevated in elevated in $78(65 \%)$ cases and were normal in 42 (35\%) cases. Khatroth $\mathrm{S}^{9}$ observed elevated serum AST and ALT in $40(66.6 \%)$ cases and they were normal in 20 (33.3\%) cases.

In our study all the 120 cases showed positive testing for NS1 antigen. In the study by Nair et a ${ }^{11}$ all their 236 adult patients were positive for NS1 antigen test. In contrast Tewari et $\mathrm{al}^{7}$ reported that only $23 \%$ (115/500; 23\%) of their patients were positive for NS1Ag.

Also based on serum IgM and IgG testing it was observed that $65 \%(78 / 120)$ cases were primary infections and $35 \%$ $(42 / 120)$ were secondary infections. Changal et $\mathrm{al}^{13}$ in their study of 114 patients observed that $66.7 \%$ (76 patients) had secondary dengue.

\section{CONCLUSION}

The clinical presentation of Dengue fever is varied and most often presents with fever, myalgia and headache. It commonly affects young adult males. It often gives rise to an elevated hematocrit, low total leucocyte count and thrombocytopenia. Serological tests help to differentiate between a primary and secondary infection which is very important as the latter is associated with hemorrhagic and shock syndromes.

\section{REFERENCES}

1. Gubler DJ. The global emergence/resurgence of arboviral diseases as public health problems. Arch Med Res 2002;33(4): 330-42.

2. Bhatt S, Gething PW, Brady OJ, Messina JP, Farlow AW, Moyes CL, et al. The global distribution and burden of dengue. Nature 2013; 496(2):504-7.

3. Park K. Epidemiology of Communicable Diseases: Dengue syndrome. In: Park's textbook of Preventiveand Social Medicine. 20th ed. Jabalpur, India: M/ sBhanarsidas Bhanot. 2009:218-22.

4. Dengue. Guidelines for diagnosis, treatment,prevention and control, 2nd Edition, World HealthOrganization, Geneva. 2009;1-144.

5. Pancharoen C, Tantawichien T, Thisyakorn C, Kulwichit W. Dnegue infection: A Global Concern J Med Assoc Thai 2005; 85 (suppl 1); S25-S33

6. Meena KC, Jelia S, Meena S, Arif M, Ajmera D, Jatav VS. A study of hematological profile in dengue fever at a tertiary care center, Kota Rajasthan. Int J Adv Med. 2016;3(3):621-624.

7. Tewari K, Tewari VV, Mehta R. Clinical and Hematological Profile of Patients with Dengue Fever at a Tertiary Care Hospital - An Observational Study.
Mediterr J Hematol Infect Dis 2018;10(1); e2018021.

8. Deshwal R, Qureshi MI, Singh R. Clinical and Laboratory Profile of Dengue Fever Journal of The Association of Physicians of India 2015; 63.

9. Khatroth S. A Study on Clinical and Hematological Profile of Dengue Fever in a Tertiary Care Hospital. IAIM, 2017; 4(8): 96-102.

10. Bhurke DP, Khan NA, Ataulla MUM. Study of clinical and haematological profile of dengue fever in a tertiary care hospital. Medpulse Internationational Journalog Medicine 2018;6(1):48-52.

11. Nair KR, Oommen S, Pai V. Clinico-Hematological Profile of Dengue Fever during the Monsoon of 2016 in Central Kerala. International Journal of Health Sciences \& Research (www.ijhsr.org) 2018;8;(12).

12. Halstead SB. Pathogenesis of dengue: challenges to molecular biology. Science. 1988;239(6):476-81.

13. Changal KH, Raina AH, Raina A, Raina M, Bashir $\mathrm{R}$, Latief $\mathrm{M}$, et al. Differentiating secondary from primary dengue using $\operatorname{IgG}$ to IgM ratio in early dengue: an observational hospital based clinico-serological study from North India. BMC Infectious Diseases 2016;16:Article number:715.

\section{Source of Support: Nil; Conflict of Interest: None}

Submitted: 24-09-2019; Accepted: 04-11-2019; Published online: 29-01-2020 